\title{
Glial-Neuronal Interactions are Impaired in the Schizophrenia Model of Repeated MK80I Exposure
}

\author{
Daniel Kondziella',2, Eiliv Brenner', Elvar M Eyjolfsson', Katarina Ryden Markinhuhta ${ }^{3}$, Maria L Carlsson ${ }^{4}$ \\ and Ursula Sonnewald*, I \\ 'Department of Neuroscience, Norwegian University of Science and Technology (NTNU), Trondheim, Norway; ${ }^{2}$ Department of Neurology and \\ Neurobiology Research Unit, Rigshospitalet, Copenhagen, Denmark; ${ }^{3}$ Carlsson Research AB, Biotech Center, Arvid Wallgrens Backe 20, \\ Göteborg, Sweden; ${ }^{4}$ Arvid Carlsson Institute, Institute of Clinical Neuroscience, Göteborg University, Medicinaregatan II, Göteborg, Sweden
}

\begin{abstract}
Schizophrenia-mimicking compounds such as phencyclidine (PCP) and MK80I are antagonists at the N-methyl-D-aspartate (NMDA) receptor and produce the whole spectrum of positive, negative, and cognitive symptoms. This is one of the most important pillars of the hypoglutamatergic hypothesis of schizophrenia. Since the synthesis of glutamate and GABA in neurons is closely connected to astrocyte metabolism, the study of astrocytic function is essential in this context. Dizocilpine-maleate (MK80 I) $(0.5 \mathrm{mg} / \mathrm{kg})$ was injected into rats every day for 6 days. The last dose was given together with $\left[1-{ }^{13} \mathrm{C}\right]$ glucose and $\left[1,2-{ }^{13} \mathrm{C}\right]$ acetate. Extracts from frontal, retrosplenial, and cingulate cortices (CRFC) and temporal lobes were examined by ${ }^{13} \mathrm{C}$ nuclear magnetic resonance spectroscopy, high pressure liquid chromatography, and light microscopy. In CRFC, significant increases in the levels of glutamate, glutathione, and taurine were seen, whereas amounts and turnover of noradrenaline, dopamine, and serotonin were unchanged. Glutamate and glutamine, derived from $\left[1,2-{ }^{13} \mathrm{C}\right]$ acetate and thus astrocytes, were significantly decreased in CRFC as compared to controls. Labeling from $\left[1-{ }^{13} \mathrm{C}\right]$ glucose and thus mostly neuronal metabolism was affected in the same brain region with decreased labeling of glutamate and GABA. The present model mimics the increased glutamate/glutamine activity found in drug-naive patients with first episode schizophrenia. Moreover, the decreased labeling indicates the transition to lower glutamatergic function seen in chronic schizophrenia patients. The disturbance in astrocytic function and the glutamine-glutamate-GABA cycle are of significant importance and might add to the malfunction of the cortico-striato-thalamo-cortical loop caused by NDMA receptor blockade.
\end{abstract}

Neuropsychopharmacology (2006) 3 I, I880-1887. doi:I0.1038/sj.npp. I 300993; published online I4 December 2005

Keywords: glutamate; GABA; glutamine; dopamine; NMDA glutamate antagonists

\section{INTRODUCTION}

Evidence is accumulating that the hypothesis of exclusive dopaminergic hyperfunction causing schizophrenia has to be revised. A more differentiated approach includes, in addition, the dopaminergic, glutamatergic, GABAergic, and serotonergic neurotransmitter systems (Carlsson et al, 2001). Particularly, glutamatergic hypofunction has been recognized to play a significant role in schizophrenia. $\mathrm{N}$-methyl-D-aspartate (NMDA) glutamate-receptor antagonists, such as phencyclidine (PCP), ketamine, or dizocilpine-maleate (MK801), have been shown to cause strong psychomimetic effects with hallucinations and psychomotor signs and have been used extensively in schizophrenia

*Correspondence: Professor U Sonnewald, Department of Neuroscience, Faculty of Medicine, NTNU, Olav Kyrres gate 3, Trondheim N-7489, Norway, Tel: + 47 73590492, Fax: + 4773598655 ,

E-mail: Ursula.Sonnewald@ntnu.no

Received 19 May 2005; revised 18 October 2005; accepted 24 October 2005

Online publication: 28 October 2005 at http://www.acnp.org/citations/ Npp I02805050335/default.pdf research. In contrast to dopaminergic agonists, which only mimic the positive symptoms of schizophrenia, NMDA antagonists produce the whole spectrum including negative and cognitive symptoms (Carlsson et al, 2001).

It has been suggested that the dysregulation of dopamine transmission in schizophrenia might be secondary to alterations in glutamatergic NMDA receptor-mediated transmission (Olney and Farber, 1995; Carlsson et al, 2004). A direct linkage between the two hypotheses has recently been shown in an experiment performed in healthy volunteers. It was observed that the amplitude of amphetamine-induced dopamine release was significantly enhanced compared to control conditions, when simultaneously the NMDA receptor-mediated transmission was decreased by ketamine administration (Kegeles et al, 2000). Thus, the elevated dopamine release seen in schizophrenic patients after amphetamine administration might very well be secondary to a failure in glutamatergic control of dopamine neurons. Analogous studies in rats support this interpretation (Miller and Abercrombie, 1996). NMDA receptor hypofunction models not involving dopamine have also been proposed (Carlsson and Carlsson, 1989, 1990; Olney, 1989). 
The synthesis of glutamate and GABA in neurons is closely connected to astrocyte metabolism and, thus, there are good reasons to postulate a role for astrocytes in the pathophysiology of glutamate/NMDA hypofunction and schizophrenia. Being the most important excitatory neurotransmitter in the mammalian CNS, glutamate and its homeostasis are crucial to brain function for several reasons. Firstly, fast removal of glutamate from the synaptic cleft by astrocytes guarantees short glutamate action on the postsynaptic target cell and thereby precise information signaling. Secondly, high extracellular concentration of glutamate is neurotoxic and it has been shown that excessive glutamate release plays a part in the pathophysiology of many brain disorders. Thirdly, neurons are not capable of net synthesis of glutamate and related metabolites, since they lack the main anaplerotic enzyme in the brain, pyruvate carboxylase (Shank et al, 1985). Thus, they depend on astrocytic supply of tricarboxylic acid (TCA) cycle intermediates since the drain of amino-acid neurotransmitters would otherwise lead to a shortage of neurotransmitter precursors (Sonnewald et al, 1993). Astrocytes release glutamine into the extracellular space, from where it is taken up by neurons and converted to glutamate and GABA or channeled into the TCA cycle via 2-oxoglutarate to provide carbon skeletons for the synthesis of metabolites. As mentioned earlier, after release from neurons, glutamate is cleared from the synapses by astrocytes, which transform glutamate to glutamine again, and the so-called 'glutamine-glutamate-cycle' is completed (Sonnewald et al, 2005).

${ }^{13} \mathrm{C}$ nuclear magnetic resonance spectroscopy (NMRS) is an excellent tool to obtain information about metabolic pathways and glial-neuronal metabolic interaction-see Sonnewald and Kondziella (2003) for a review. The natural abundance of ${ }^{13} \mathrm{C}$ is only $1.1 \%$, thus ${ }^{13} \mathrm{C}$-labeled precursors and products are easily detected. When $\left[1,2-{ }^{13} \mathrm{C}\right]$ acetate and $\left[1-{ }^{13} \mathrm{C}\right]$ glucose are given simultaneously, it is possible to study astrocytic and neuronal metabolism in the same animal. This is because acetate is exclusively taken up by astrocytes, while the major part of acetyl-CoA derived from glucose is metabolized in neurons (Taylor et al, 1996). Thus, ${ }^{13} \mathrm{C}$ NMRS provides a more dynamic picture of metabolic changes compared to ${ }^{1} \mathrm{H}$ NMRS and high pressure liquid chromatography (HPLC). MK801 is one of the best-characterized noncompetitive antagonists of the PCP-binding site of the NMDA receptor, which is also present on astrocytes (Krebs et al, 2003). Since it is even more selective than PCP (Carlsson et al, 2001), MK801 is a widely studied substance in experimental research of both schizophrenia and glutamate neurotoxicity. It causes behavioral changes in rodents such as hyperlocomotion, stereotyped behavior, head weaving, and ataxia (Loscher and Honack, 1991). Altered cerebral metabolism with excessive cerebral glucose supply has been reported by Loubinoux et al (1994). MK801 is able to minimize cell damage in the rodent hippocampus during ischemia, and also to induce neuronal degeneration. Toxic effects of MK801 were first observed and are most pronounced in the retrosplenial and cingulate cortices (Olney et al, 1989; Wozniak et al, 1998). With increasing MK801 concentrations, alterations were also seen in other brain areas including entorhinal and piriform cortices, dentate gyrus, and amygdala (Horvath et al, 1997).

Since the diagnosis of schizophrenia requires recurrent episodes of psychoses, a protocol with repeated injections of MK801 was chosen in the present study. We induced a state of NMDA receptor hypofunction in rats by injection of MK801 every day for 6 days. Then astrocytic-neuronal interactions in frontal, retrosplenial, and cingulate cortices and temporal lobe were examined by means of NMRS, HPLC, and light microscopy to test the hypothesis that glial-neuronal metabolism is disturbed in the schizophrenia model of repeated MK801 treatment.

\section{MATERIALS AND METHODS}

\section{Materials}

Male Sprague-Dawley rats with an average weight of $250 \mathrm{~g}$ were obtained from Möllegaard Breeding Centre, Copenhagen, Denmark. $\left[1-{ }^{13} \mathrm{C}\right]$ glucose, $\left[1,2-{ }^{13} \mathrm{C}\right]$ acetate (both $99 \%{ }^{13} \mathrm{C}$ enriched), and $\mathrm{D}_{2} \mathrm{O}(99.9 \%)$ were purchased from Cambridge Isotopes Laboratories (Woburn, MA, USA); ethylene glycol from Merck (Darmstadt, Germany). $o$-Phthaldialdehyde and MK801 (Dizocilpine; [5R, 10S][ + ]-5-methyl-10,11-dihydro-5H-dibenzo[a,d]cyclohepten5,10-imine) were from Sigma-Aldrich, St Louis, MO, USA. All other chemicals were of the purest grade available from local commercial sources.

\section{Methods}

All animal procedures were approved by the Norwegian Animal Research Authority. Prior to experiments, the animals received food and water ad libitum and were kept at a light/dark cycle of $12 \mathrm{~h}$, humidity $60 \%$, temperature $22^{\circ} \mathrm{C}$. During the experiment, the animals were housed in individual cages. Saline (10 animals) or MK801 (10 animals; $0.5 \mathrm{mg} / \mathrm{kg}$ body weight) was administered intraperitoneally (i.p.) every day for 6 days. The last dose of MK801 or saline was given in seven (MK801) and five (saline) rats together with $\left[1-{ }^{13} \mathrm{C}\right]$ glucose $(543 \mathrm{mg} / \mathrm{kg}, \quad 0.3 \mathrm{M}$ solution) and $\left[1,2-{ }^{13} \mathrm{C}\right]$ acetate $(504 \mathrm{mg} / \mathrm{kg}, 0.6 \mathrm{M}$ solution) i.p. followed by decapitation $20 \mathrm{~min}$ later. Brains from these animals were analyzed by HPLC and ${ }^{13} \mathrm{C}$ NMRS. The heads were snap frozen in liquid nitrogen and stored at $-80^{\circ} \mathrm{C}$. Brains were removed, and two different areas of each hemisphere were dissected. The first area included the cingulate, the retrosplenial, and the frontal cortices (CRFC). The second area, which in the present study will be referred to as the temporal lobe, was dissected by a horizontal cut from the most lateral point of the hemisphere extending approximately $3 \mathrm{~mm}$ medially and a second sagittal cut extending ventrally through the whole brain. The resulting sample consisted of the temporal cortex, piriform cortex, entorhinal cortex, amygdala, and parts of the hippocampus. The dissection was performed on ice while the brains were still frozen, and lasted a maximum of $3 \mathrm{~min}$. After dissection, brain tissue was homogenized in $7 \%(\mathrm{w} / \mathrm{v})$ perchloric acid and centrifuged at $4000 \mathrm{~g}$ for $5 \mathrm{~min}$. The procedure was repeated, the supernatants pooled and neutralized with $1 \mathrm{M}$ $\mathrm{KOH}$ followed by lyophilization. 


\section{Histology}

Three MK801-treated rats and five controls did not receive $\left[1-{ }^{13} \mathrm{C}\right]$ glucose and $\left[1,2-{ }^{13} \mathrm{C}\right]$ acetate in their last injection. They were killed with an overdose of equithisin and underwent cardiac perfusion with saline and $4 \%$ formaldehyde. Brains were removed immediately after perfusion and stored in the same fixative until slicing. Frozen sections were cut and stained with hematoxilin-eosin or cresyl violet. Using the atlas of Paxinos and Watson (1998) CRFC, temporal lobes and hippocampus were identified and examined by light microscopy for signs of neuronal degeneration such as intracytoplasmatic vacuoles, remnant nuclear debris, brightly eosinophilic cytoplasm, and local glial reaction, which have been described earlier (Olney, 1989).

\section{HPLC}

Total amounts of amino acids and total glutathione were determined by HPLC using the HP 1100 System from Agilent (Palo Alto, CA, USA), with fluorescence detection, after derivatization with $o$-phthaldialdehyde. Separation was performed on a ZORBAX SB-C18 $(4.6 \times 250 \mathrm{~mm}, 5 \mathrm{~mm})$ column from Agilent with $50 \mathrm{mM}$ sodium acetate buffer $(\mathrm{pH}$ 7.0) and methanol as eluents.

The monoamine transmitter substances (NA, DA, 5-HT) and acid metabolites (DOPAC, 5-HIAA, HVA) were quantified in brain tissue homogenates by HPLC separations and electrochemical detection. The analytical method is based on two chromatographic separations for amines and acids. Both systems are equipped with a reverse phase coloumn (Luna C18(2), dp $3 \mu \mathrm{m}, 50 \times 2 \mathrm{~mm}$ i.d., Phenomex), and electrochemical detection is accomplished at two potentials on glassy carbon electrodes (MF-1000, Bioanalytical Systems, Inc.). The aqueous mobile phase $(0.4 \mathrm{ml} / \mathrm{min})$ for the acid system contains citric acid $14 \mathrm{mM}$, sodium citrate $10 \mathrm{mM}, \mathrm{MeOH} 15 \%(\mathrm{v} / \mathrm{v})$, and EDTA $0.1 \mathrm{mM}$. Detection potentials relative to $\mathrm{Ag} / \mathrm{AgCl}$ reference are 0.45 and $0.6 \mathrm{~V}$. The aqueous ion pairing mobile phase $(0.5 \mathrm{ml} / \mathrm{min})$ for the amine system contains citric acid $5 \mathrm{mM}$, sodium citrate $10 \mathrm{mM}, \mathrm{MeOH} 9 \%$ (v/v), decane sulfonic acid $0.45 \mathrm{mM}$, and EDTA $0.1 \mathrm{mM}$. Detection potentials relative to $\mathrm{Ag} / \mathrm{AgCl}$ reference are 0.45 and $0.65 \mathrm{~V}$.

\section{${ }^{13}$ C NMR Spectroscopy}

Proton decoupled $150.92 \mathrm{MHz}{ }^{13} \mathrm{C}$ NMR spectra were obtained using a Bruker DRX-600 spectrometer after the samples had been redissolved in $200 \mu \mathrm{D}_{2} \mathrm{O}$ (deuterated water) containing ethylene glycol $0.1 \%$ as an internal standard. Scans were accumulated with a $30^{\circ}$ pulse angle and $30 \mathrm{kHz}$ spectral width with $64 \mathrm{~K}$ data points. The number of scans was typically 10000 . The acquisition time was $1.08 \mathrm{~s}$, the relaxation delay $0.5 \mathrm{~s}$. Factors for nuclear Overhauser and relaxation effects were applied to all spectra.

\section{Labeling Patterns}

Label from $\left[1-{ }^{13} \mathrm{C}\right]$ glucose can be quantified by analyzing the singlet peaks in the different resonances (Figure 1) (Sonnewald and Kondziella, 2003). In contrast, the doublets seen in the spectrum (Figure 1) are mostly derived from $\left[1,2-{ }^{13} \mathrm{C}\right]$ acetate and thus astrocytic metabolism (Waniewski and Martin, 1998). Glutamine is labeled more from $\left[1,2-{ }^{13} \mathrm{C}\right]$ acetate (doublet) than $\left[1-{ }^{13} \mathrm{C}\right]$ glucose (singlet); the opposite is the case for glutamate and GABA. Alanine, lactate, $N$-acetylaspartate (NAA) in the C-6 position, and succinate are mainly labeled from glucose. Creatine, taurine, inositol, and the aspartate group in NAA are not labeled; the naturally abundant ${ }^{13} \mathrm{C}$ gives rise to the observed singlets (Figure 1). Since both acetyl-CoA and oxalacetate can be labeled or unlabeled, the number of possible isotopomers of the TCA cycle-derived metabolites is large and only compounds derived from the first and the second turns are presented in Figure 2. In addition to analysis of the single peaks, conclusions about the predominant metabolic pathways can be drawn from metabolic ratios (see below). $\left[1-{ }^{13} \mathrm{C}\right]$ glucose is converted to pyruvate via glycolysis and can form $\left[3-{ }^{13} \mathrm{C}\right]$ alanine and $\left[3-{ }^{13} \mathrm{C}\right]$ lactate. Pyruvate may enter the TCA cycle via $\left[2-{ }^{13} \mathrm{C}\right]$ acetyl-CoA, which will lead to the formation of $\left[4-{ }^{13} \mathrm{C}\right]$ glutamate and glutamine or $\left[2-{ }^{13} \mathrm{C}\right] \mathrm{GABA}$. After the second turn of the TCA cycle, this label will be in the $\left[2-{ }^{13} \mathrm{C}\right]$ or $\left[3-{ }^{13} \mathrm{C}\right]$ positions of glutamate and glutamine or in the $\left[3-{ }^{13} \mathrm{C}\right]$ or $\left[4-{ }^{13} \mathrm{C}\right]$ positions of GABA. Alternatively, pyruvate can be carboxylated by pyruvate carboxylase (PC) to oxalacetate, which will lead to the synthesis of $\left[2-{ }^{13} \mathrm{C}\right]$ glutamate and glutamine or $\left[4-{ }^{13} \mathrm{C}\right] \mathrm{GABA}$. $\left[1,2-{ }^{13} \mathrm{C}\right]$ acetate can also be converted to acetyl-CoA, however, the product, $\left[1,2-{ }^{13} \mathrm{C}\right]$ acetyl-CoA, will have two ${ }^{13} \mathrm{C}$ atoms resulting in doublet formation. Thus, $\left[4,5-{ }^{13} \mathrm{C}\right]$ glutamate and glutamine or $\left[1,2-{ }^{13} \mathrm{C}\right] \mathrm{GABA}$ are formed (Figure 2). After the second turn of the TCA cycle, this label will be in the $\left[1,2-{ }^{13} \mathrm{C}\right]$ or $\left[3-{ }^{13} \mathrm{C}\right]$ positions of glutamate and glutamine and the $\left[2-{ }^{13} \mathrm{C}\right]$ or $\left[3-{ }^{13} \mathrm{C}\right]$ positions of GABA.

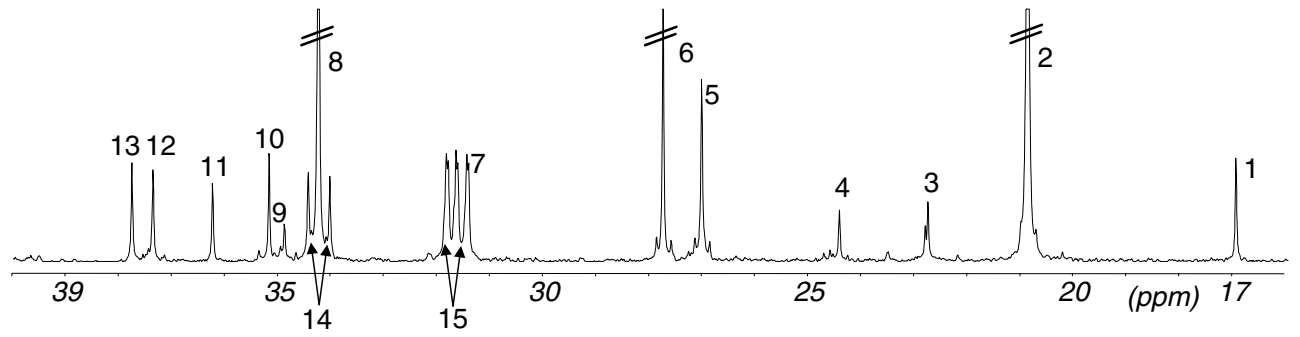

Figure I ${ }^{13} \mathrm{C}$ NMR spectrum of temporal lobe extracts from rats injected with MK80I together with $\left[1,2-{ }^{13} \mathrm{C}\right]$ acetate and $\left[1-{ }^{13} \mathrm{C}\right] g$ lucose. Peak assignments: I: alanine C-3; 2: lactate C-2; 3: N-acetyl-aspartate C-6; 4: GABA C-3; 5: glutamine C-3; 6: glutamate C-3; 7: glutamine C-4; 8: glutamate C-4; 9: succinate C-2/C-3; I0: GABA C-2; II: aspartate C-3; I2: GABA C-4; I3: N-acetyl-aspartate C-6; I4: [4,5- ${ }^{13}$ C]glutamate; I5: [4,5- ${ }^{13}$ C]glutamine. 
1st turn TCA

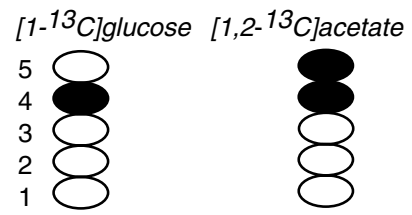

Glutamate/glutamine

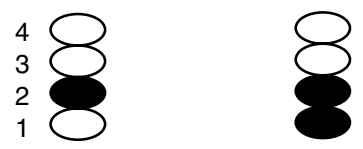

GABA 2nd turn TCA
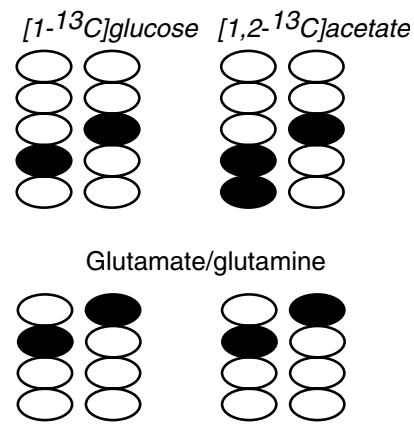

GABA
Figure $2{ }^{13} \mathrm{C}$-labeling patterns in glutamate, glutamine, and GABA from $\left[1-{ }^{3} \mathrm{C}\right] g$ lucose or $\left[1,2-{ }^{13} \mathrm{C}\right]$ acetate. Full circle represents ${ }^{13} \mathrm{C}$ and empty circle ${ }^{12} \mathrm{C}$. First turn tricarboxylic acid (TCA) cycle: labeled acetyl-CoA condensing with unlabeled oxaloacetate; second turn: unlabeled acetylCoA condensing with labeled oxaloacetate.

\section{Metabolic Ratios}

The acetate $v s$ glucose utilization ratio is an estimation of the relative contribution from neurons and astrocytes to glutamate, glutamine, and GABA formation (Taylor et al, 1996). Incorporation of $\left[1,2-{ }^{13} \mathrm{C}\right]$ acetate yields $\left[4,5-{ }^{13} \mathrm{C}\right]$ glutamate (peak 14 Figure 1), $\left[4,5-{ }^{13} \mathrm{C}\right]$ glutamine (peak 15 Figure 1), and $\left[1,2-{ }^{13} \mathrm{C}\right] \mathrm{GABA}$, whereas $\left[1-{ }^{13} \mathrm{C}\right]$ glucose gives rise to $\left[4-{ }^{13} \mathrm{C}\right]$ glutamate, $\left[4-{ }^{13} \mathrm{C}\right]$ glutamine, and $\left[2-{ }^{13} \mathrm{C}\right] \mathrm{GABA}$. The acetate $v s$ glucose utilization ratios are expressed as $\left[4,5-{ }^{13} \mathrm{C}\right]$ glutamate (glutamine)/[4- $\left.{ }^{13} \mathrm{C}\right]$ glutamate (glutamine), and $\left[1,2-{ }^{13} \mathrm{C}\right] \mathrm{GABA} /\left[2-{ }^{13} \mathrm{C}\right] \mathrm{GABA}$.

The ${ }^{13} \mathrm{C}$ cycling ratio gives an indication of how long label stays in the TCA cycle before incorporation into glutamate and glutamine. The cycling ratio for ${ }^{13} \mathrm{C}$ from $\left[1,2-{ }^{13} \mathrm{C}\right]$ acetate was calculated as follows: $\left[1,2{ }^{13} \mathrm{C}\right]$ glutamate (glutamine $/\left[4,5-{ }^{13} \mathrm{C}\right]$ glutamate (glutamine). The cycling ratio for ${ }^{13} \mathrm{C}$ from $\left[1-{ }^{13} \mathrm{C}\right]$ glucose was calculated as $\left(\left[3-{ }^{13} \mathrm{C}\right]\right.$ glutamate (glutamine) $-\left[1,2-{ }^{13} \mathrm{C}\right]$ glutamate (glutamine) $/\left[4{ }^{-13} \mathrm{C}\right]$ glutamate (glutamine). Ratios of pyruvate carboxylase and pyruvate dehydrogenase ( $\mathrm{PC} / \mathrm{PDH}$ ratios) give information about the importance of replacement of intermediates lost from the TCA cycle and can be calculated as $\left(\left[2-{ }^{13} \mathrm{C}\right]\right.$ glutamate (glutamine) $-\left[3-{ }^{13} \mathrm{C}\right]$ glutamate (glutamine) $) /\left[4{ }^{13} \mathrm{C}\right]$ glutamate (glutamine). The labeling of GABA from the second turn is identical for $\left[1-{ }^{13} \mathrm{C}\right]$ glucose and $\left[1,2-{ }^{13} \mathrm{C}\right]$ acetate.

\section{Data Analysis}

The amounts of ${ }^{13} \mathrm{C}$ in the different metabolites were quantified from integrals of the relevant peaks obtained from NMR spectra with ethylene glycol as an internal standard. All results are given as mean \pm standard deviation. Statistics were performed using the two-tailed, unpaired Student's $t$-test; $p<0.05$ was regarded as significant.

\section{RESULTS}

MK801 induced hyperlocomotion, ataxia, abducted hind limbs, flat body posture, and stereotyped behavior such as head waving, which were characterized by considerable interand intrasubject variability. Injection of $\left[1-{ }^{13} \mathrm{C}\right]$ glucose and $\left[1,2-{ }^{13} \mathrm{C}\right]$ acetate lead to efficient labeling of many metabolites (Figure 1). Particularly, labeling of glutamate and glutamine C-3 and C-4, GABA C-2 and C-3, aspartate, and lactate C-3 are shown in Figure 1. Labeling patterns from $\left[1{ }^{13} \mathrm{C}\right]$ glucose and $\left[1,2-{ }^{13} \mathrm{C}\right]$ aspartate from the first and second turns of the TCA cycle are shown in Figure 2.

MK801 affected the CRFC to a much greater extent than the temporal lobe. As can be seen in Table 1, there was a significant increase in the levels of glutamate, taurine, and glutathione in the CRFC compared to control. Concentrations of serine, aspartate, alanine, $\mathrm{NAD}^{+}, \mathrm{ADP}$ plus ATP (data not shown), and NAA were not affected by MK801. Levels of noradrenaline, serotonin, and dopamine remained unchanged (data not shown). This was also true for the turnover of dopamine (DOPAC/DA and HVA/DA) and serotonin (5-HIAA/5-HT). In the temporal lobe, only the amount of inositol was increased after MK801. The amounts of $\left[4,5-{ }^{13} \mathrm{C}\right]$ glutamate and $\left[4,5-{ }^{13} \mathrm{C}\right]$ glutamine, derived from $\left[1,2-{ }^{13} \mathrm{C}\right]$ acetate, were significantly decreased in CRFC as compared to controls (Table 2). Label from $\left[1{ }^{13} \mathrm{C}\right]$ glucose was affected in the same brain region of MK801-treated rats with decreases of $\left[4-^{13} \mathrm{C}\right]$ glutamate, $\left[2-{ }^{13} \mathrm{C}\right] \mathrm{GABA}$, and $\left[4-{ }^{13} \mathrm{C}\right] \mathrm{GABA}$, whereas in the temporal lobe both $\left[1,2-{ }^{13} \mathrm{C}\right]$ acetate and $\left[1-{ }^{13} \mathrm{C}\right]$ glucose-derived metabolites were not altered. Concentration of $\left[3{ }^{-13} \mathrm{C}\right]$ lactate was unchanged in both areas (data not shown). In Table 3, it can

Table I Total Amounts ( $\mu$ mol/g Brain Tissue) of Metabolites (a) and Turnover Rates of Dopamine and Serotonin (b) in Brain Extracts of Controls $(n=5)$ and MK80I-Treated Rats $(n=7)$

\begin{tabular}{|c|c|c|c|c|}
\hline & \multicolumn{2}{|c|}{ CRFC } & \multicolumn{2}{|c|}{ Temporal lobe } \\
\hline & Control & MK80I & Control & MK80I \\
\hline \multicolumn{5}{|l|}{ (a) Metabolites } \\
\hline Glutamate & $7.80 \pm 1.9$ & $10.13 \pm 2.3^{* * *}$ & $8.09 \pm 1.4$ & $9.36 \pm 1.4$ \\
\hline GABA & $1.48 \pm 0.5$ & $1.89 \pm 0.7$ & $2.02 \pm 0.5$ & $2.16 \pm 0.6$ \\
\hline Glutamine & $2.59 \pm 0.9$ & $3.22 \pm 1.1$ & $3.03 \pm 0.9$ & $2.90 \pm 0.4$ \\
\hline Glutathione & $1.02 \pm 0.2$ & $1.30 \pm 0.3 *$ & $1.15 \pm 0.2$ & $1.05 \pm 0.2$ \\
\hline Taurine & $4.35 \pm 0.8$ & $5.20 \pm 0.9 *$ & $4.85 \pm 0.7$ & $5.41 \pm 0.7$ \\
\hline $\mathrm{N}$-acetylaspartate & $6.00 \pm 0.8$ & $5.40 \pm 1.1$ & $5.72 \pm 0.8$ & $5.00 \pm 0.5$ \\
\hline Inositol & $7.01 \pm 0.7$ & $6.99 \pm 0.6$ & $8.26 \pm 0.8$ & $9.30 \pm 0.6$ \\
\hline \multicolumn{5}{|l|}{ (b) Turnover rates } \\
\hline DOPAC/DA & $0.65 \pm 0.2$ & $0.68 \pm 0.2$ & $0.13 \pm 0.1$ & $0.14 \pm 0.1$ \\
\hline HVA/DA & $1.03 \pm 0.4$ & $0.99 \pm 0.2$ & $0.11 \pm 0.1$ & $0.13 \pm 0.1$ \\
\hline 5-HIAA/5-HT & $0.32 \pm 0.2$ & $0.55 \pm 0.2$ & $0.74 \pm 0.2$ & $0.65 \pm 0.1$ \\
\hline
\end{tabular}

Rats received MK80I $(0.5 \mathrm{mg} / \mathrm{kg})$ or saline i.p. every $24 \mathrm{~h}$ for 6 days. On day six $\left[1,2-{ }^{13} \mathrm{C}\right]$ acetate and $\left[1-{ }^{13} \mathrm{C}\right] g$ lucose were administered (see Materials and Methods for details). All results were obtained by HPLC with the exception for levels of $\mathrm{N}$-acetylaspartate and inositol (assessed by ${ }^{13} \mathrm{C} N M R$ ). The results are expressed as mean $\pm S D$ and were analyzed with the two-tailed unpaired Student's t-test. Abbreviations: $C R F C=$ frontal/cingulate/retrosplenial cortex; $\mathrm{DA}=$ dopamine; DOPAC = dihydroxyphenylacetic acid; HVA = homovanillic acid; 5-HT = serotonin; 5-HIAA = 5-hydroxyindoleacetic acid; n.d. = not detected; $*$ $p<0.05 ; * * * 0.025$ 
be seen that following MK801, the cycling ratio for ${ }^{13} \mathrm{C}$ from $\left[1-{ }^{13} \mathrm{C}\right]$ glucose was increased for glutamate in both the investigated brain areas. Moreover, acetate/glucose ratios for glutamate and glutamine were decreased in the CRFC. However, an increase of the cycling ratio for ${ }^{13} \mathrm{C}$ from $\left[1,2-{ }^{13} \mathrm{C}\right]$ acetate was found in the CRFC for glutamine. PC/ $\mathrm{PDH}$ ratios were not changed (data not shown).

Eosin- and cresyl violet-stained histological slices from CRFC, hippocampus, and TE were examined by light microscopy, but no morphological changes were found between MK801-treated rats and controls.

\section{DISCUSSION}

In the present study repeated injections of MK801 increased amounts of glutamate in CRFC, whereas labeling of glutamate and glutamine from $\left[1,2-{ }^{13} \mathrm{C}\right]$ acetate and thus astrocytic metabolism was significantly decreased in CRFC.

Table 2 Amounts (nmol/g) of ${ }^{13} \mathrm{C}$ of Tissue in Brain Extracts from Controls $(n=5)$ and MK80I-Treated Rats $(n=7)$

\begin{tabular}{|c|c|c|c|c|}
\hline \multirow{2}{*}{ Metabolites } & \multicolumn{2}{|c|}{ CRFC } & \multicolumn{2}{|c|}{ Temporal lobe } \\
\hline & Control & MK80I & Control & MK80I \\
\hline \multicolumn{5}{|l|}{$\left[1,2^{13} \mathrm{C}\right]$ acetate } \\
\hline$\left[4,5-{ }^{13} \mathrm{C}\right]$ Glutamate & $260.8 \pm 44.6$ & $201.0 \pm 23.3 *$ **** & $198.0 \pm 29.4$ & $201.5 \pm 24.3$ \\
\hline$\left[1,2-{ }^{13} \mathrm{C}\right] \mathrm{GABA}$ & $22.6 \pm 5.7$ & $20.8 \pm 6.1$ & $29.4 \pm 8.5$ & $25.2 \pm 6.2$ \\
\hline$\left[4,5-{ }^{13} \mathrm{C}\right]$ Glutamine & $324.0 \pm 59.5$ & $268.4 \pm 21.1$ *** & $306.5 \pm 50.2$ & $285.6 \pm 28.6$ \\
\hline \multicolumn{5}{|l|}{$\left[1-^{13} \mathrm{C}\right] g /$ cose } \\
\hline$\left[4-^{13} \mathrm{C}\right]$ Glutamate & $800.7 \pm 137.1$ & $666.7 \pm 68.5^{*}$ & $634.0 \pm 80.5$ & $622.9 \pm 97.8$ \\
\hline$\left[2-{ }^{13} \mathrm{C}\right] \mathrm{GABA}$ & $76.2 \pm 16.9$ & $61.1 \pm 9.3^{*}$ & $91.0 \pm 14.8$ & $76.0 \pm 16.7$ \\
\hline$\left[4-{ }^{13} \mathrm{C}\right]$ Glutamine & $163.8 \pm 22.2$ & $166.0 \pm 18.4$ & $146.8 \pm 17.5$ & $157.3 \pm 26.6$ \\
\hline
\end{tabular}

All results were obtained by ${ }^{13} \mathrm{C}$ NMR spectroscopy. Abbreviations: see Table I. For details, see Materials and Methods. ${ }^{*} p<0.05$; ${ }^{*} p<0.025$; ${ }^{*} * * * 0.01$.
Labeling from $\left[1-{ }^{13} \mathrm{C}\right]$ glucose and thus mostly neuronal metabolism was affected as well in the same brain region with decreased labeling of glutamate and GABA as compared to controls. A tentative conclusion, as will be discussed below, is that repeated injection of MK801 is a good animal model for first episode schizophrenics and might give insight into the transition from the acute to the chronic stage.

\section{Glutamate-Glutamine-GABA Cycle and Glial-Neuronal Interactions}

Using HPLC we found increased levels of glutamate in the CRFC. As pointed out in the Introduction, glutamate and glutamine are very closely linked metabolically. In an in vivo ${ }^{1} \mathrm{H}$ NMRS study it was suggested that the glutamine signal in spectra of anterior cingulate and thalamus of drugnaive first episode schizophrenia patients was increased compared to age-matched healthy controls (Theberge et al, 2002). However, using ${ }^{1} \mathrm{H}$ NMRS at low field strength it is not possible to fully separate glutamate and glutamine signals, whereas there is no overlap between these two amino-acid signals using high field ${ }^{1} \mathrm{H}$ NMRS or HPLC. Thus, it is possible that also in these cited studies glutamate instead of glutamine was enhanced. In contrast to drug naive patients with first episode schizophrenia, lower levels of glutamine and glutamate were found in the left anterior cingulate cortex of patients with chronic schizophrenia compared to healthy volunteers (Theberge et al, 2003). In view of the decrease in labeling of glutamate and glutamine observed in this study, it is tempting to speculate that decreased amounts of these metabolites would eventually result, had the rats been injected with MK801 for an even longer period. This in turn would mirror the finding of decreased glutamate and glutamine in chronic patients. Even though chronic schizophrenia in humans develops over a much longer time period, it is conceivable that the present model of repeated MK801 injection can give insight into the transition mechanisms of first episode to chronic state schizophrenia.

Table 3 Acetate/Glucose Utilization Ratios and Cycling Ratios from $\left[1,2-{ }^{13} \mathrm{C}\right]$ Acetate and $\left[1-{ }^{13} \mathrm{C}\right]$ Glucose from Controls $(n=5)$ and MK80I-Treated Rats $(n=7)$

\begin{tabular}{|c|c|c|c|c|c|c|}
\hline & \multicolumn{3}{|c|}{ CRFC } & \multicolumn{3}{|c|}{ Temporal lobe } \\
\hline & $\begin{array}{c}\text { Acetate/glucose } \\
\text { utilization }\end{array}$ & $\begin{array}{l}\text { Glucose } \\
\text { cycling }\end{array}$ & $\begin{array}{l}\text { Acetate } \\
\text { cycling }\end{array}$ & $\begin{array}{c}\text { Acetate/glucose } \\
\text { utilization }\end{array}$ & $\begin{array}{l}\text { Glucose } \\
\text { cycling }\end{array}$ & $\begin{array}{l}\text { Acetate } \\
\text { cycling }\end{array}$ \\
\hline \multicolumn{7}{|l|}{ MK80I } \\
\hline Glutamate & $0.29 \pm 0.0 * *$ & $0.53 \pm 0.0 * * * *$ & $0.39 \pm 0.1$ & $0.31 \pm 0.0$ & $0.41 \pm 0.0^{*}$ & $0.34 \pm 0.1$ \\
\hline Glutamine & $1.62 \pm 0.1$ 米*** & $0.83 \pm 0.0$ & $0.33 \pm 0.1^{*}$ & $2.12 \pm 0.5$ & $0.02 \pm 0.1$ & $0.35 \pm 0.1$ \\
\hline GABA & $0.35 \pm 0.1$ & $0.94 \pm 0.2$ & ND & $0.33 \pm 0.1$ & $0.83 \pm 0.1$ & ND \\
\hline \multicolumn{7}{|l|}{ Controls } \\
\hline Glutamate & $0.33 \pm 0.0$ & $0.46 \pm 0.0$ & $0.34 \pm 0.1$ & $0.33 \pm 0.1$ & $0.33 \pm 0.0$ & $0.33 \pm 0.0$ \\
\hline Glutamine & $1.97 \pm 0.2$ & $0.77 \pm 0.1$ & $0.27 \pm 0.1$ & $1.85 \pm 0.3$ & $0.15 \pm 0.1$ & $0.31 \pm 0.1$ \\
\hline GABA & $0.31 \pm 0.0$ & $0.80 \pm 0.1$ & ND & $0.33 \pm 0.1$ & $0.85 \pm 0.1$ & ND \\
\hline
\end{tabular}

All results were obtained by ${ }^{13} \mathrm{C}-\mathrm{NMR}$ spectroscopy. Abbreviations: see Table I. For details see Materials and Methods. $* p<0.05 ; * * 2<0.025 ; * * * *<0.01$. 
Whereas levels of glutamate were increased in the CRFC following repeated MK801 administration, after a single dose of MK801, an increase was instead found in the temporal lobe (Brenner et al, 2005). In contrast to acute administration, where the amounts of labeled glutamate were not altered, repeated MK801 injections lead to decreases of both $\left[4-{ }^{13} \mathrm{C}\right]$ glutamate and $\left[4,5-{ }^{13} \mathrm{C}\right]$ glutamate in the CRFC. The fact that the amount of $\left[4-{ }^{13} \mathrm{C}\right]$ glutamine was unchanged indicates that transfer of glutamate from neurons to astrocytes was not altered and thus an intriguing explanation might be that glutamate, released from neurons, accumulates in astrocytes. The decreased amount of $\left[4,5-{ }^{13} \mathrm{C}\right]$ glutamate points towards impaired efflux of $\left[4,5{ }^{13} \mathrm{C}\right]$ glutamine from astrocytes to neurons, suggesting that the glutamine-glutamate cycle is disturbed during repeated NMDA-antagonist administration (Kosenko et al, 2003) and possibly schizophrenia. In line with this is the decrease of the acetate $v s$ glucose utilization ratio for glutamate, which indicates lowered astrocytic contribution to glutamate formation. However, the reason for the increase in TCA cycling of precursors for glutamate from $\left[1-{ }^{13} \mathrm{C}\right]$ glucose is not clear, but implies that label stays longer in the neuronal TCA cycle before incorporation into glutamate. That the glutamate-glutamine cycle is disrupted in schizophrenia patients as well is supported by the finding that activity of glutamine synthetase is decreased in brains of schizophrenic patients analyzed post mortem (Burbaeva et al, 2003). In this context, it must be recalled, however, that treatment with neuroleptics might contribute to a disrupted glutamate-glutamine cycle.

Glutamine released by astrocytes serves additionally as a precursor for the inhibitory neurotransmitter GABA via glutamate (Sonnewald et al, 1993). Therefore, the concept of the glutamate-glutamine cycle has been extended to the glutamate-glutamine-GABA cycle (Sonnewald et al, 2005). The amount of GABA and $\left[1,2-{ }^{13} \mathrm{C}\right] \mathrm{GABA}$ from $\left[1,2-{ }^{13} \mathrm{C}\right]$ acetate remained unchanged, whereas, $\left[2-{ }^{13} \mathrm{C}\right] \mathrm{GABA}$ was decreased in the CRFC in the present study. Thus, GABA turnover from $\left[1-{ }^{13} \mathrm{C}\right]$ glucose was affected, which corroborates recent reports of impaired activity of glutamic acid decarboxylase (GAD) in schizophrenic patients (Guidotti et al, 2000; Volk et al, 2000; Dracheva et al, 2004). In this context, it is noteworthy that a decrease in $\mathrm{GAD}_{67}$ has been suggested as a link between the glutamatergic and dopaminergic theories of psychosis (Hossein Fatemi et al, 2005).

It is interesting that the changes in the model of repeated MK801 administration did not occur in the temporal lobe as seen with acute MK801 administration (Brenner et al, 2005), but in the CRFC. This is in accordance with the findings in human schizophrenia patients (Stanley et al, 1996; Theberge et al, 2003; Ohrmann et al, 2005) and healthy subjects exposed to ketamine (Rowland et al, 2005). Thus, the repeated administration might generate a better schizophrenia model than acute exposure and emphasizes the importance of the frontal and retrosplenial/cingulate cortex for the pathophysiology of schizophrenia.

\section{Dopamine and its Interaction with Glutamate Metabolism}

Surprisingly, in contrast to the consequences of acute PCP exposure, repeated PCP administrations lowered dopamine turnover in the monkey and rat cortex (Jentsch et al, 1997a, b). NMDA antagonism appeared to be at least partly responsible for this effect, since a comparable, although smaller, reduction in dopamine turnover in the cortex of rats was seen after repeated MK801 administration (Jentsch et al, 1998). In these studies as well as in ours, absolute dopamine levels were unaltered. However, in the present study, metabolite/transmitter ratios (DOPAC/DA and HVA/ DA) were unchanged, indicating that dopamine turnover was unaffected. Jentsch and Roth (1999) proposed that the absence of PCP-induced changes in tissue concentrations of dopamine itself implied that no direct neurotoxic insult to dopaminergic neurons occurred during the repeated PCP administration. A loss of dopaminergic neurons would otherwise be accompanied by a loss of dopamine content in the terminal fields of these projection neurons (Jentsch and Roth, 1999).

Decreased corticostriatal glutamatergic neurotransmission results in decreased negative feedback mediated via the so-called indirect striatothalamic pathway (Carlsson, 1993). Consequently, thalamic filter function is impaired. If glutamatergic NMDA receptors are dysfunctional in schizophrenia, the present and other studies suggest that secondary disturbances in glial-neuronal interactions and the glutamine-glutamate cycle may occur in this disorder (Do et al, 2000; Theberge et al, 2002, 2003). This may then contribute to imbalance of the cortico-striato-thalamocortical feedback as also suggested by Laruelle et al. (2003).

As in the study with acute exposure to MK801 (Brenner et al, 2005), glutathione concentration was increased during repeated MK801 injection, however, this time in the CRFC. Being the main antioxidant in the brain (Dringen and Hirrlinger, 2003), glutathione protects cells from damage by reactive oxygen species originating partly from dopamine metabolism. Decreased glutathione levels might lead to degenerative processes in the surroundings of dopaminergic terminals with loss of connectivity as a result. The increased level of glutathione in the present study could point to a decreased use of antioxidants, possibly caused by diminished NO production due to lower $\mathrm{Ca}^{2+}$ concentration and NMDA blockade. Interestingly, there is evidence that glutathione also enhances the NMDA receptor response to glutamate (Janaky et al, 1993). However, in cerebrospinal fluid of drug-free schizophrenic patients, a significant decrease in the level of glutathione was observed (Do et al, 2000). Combined with our results, this could indicate that transport of glutathione from the brain to CSF is disturbed.

\section{Energy Metabolism and Histology}

On histologic examinations, no signs of neuronal degeneration were found, which is in agreement with observations by other authors (Brosnan-Watters et al, 1999; Jentsch and Roth, 1999). Reversible changes were seen in rat brain exposed to both chronic and acute NMDA antagonist administration with neuronal vacuolar degeneration, remnant nuclear debris, and local glial reaction (Wozniak et al, 1996; Brosnan-Watters et al, 1999) and appeared at the earliest $4 \mathrm{~h}$ after MK801 administration (Fix et al, 1993). Permanent damage was only seen at doses 20 times higher than the one used in the present study (Wozniak et al, 
1998). Since MK801 administration at low doses induces only reversible morphological changes, neuronal damage must be considered functional, not structural. Especially in light of the normal NAA concentration observed in the present study, it appears that NAA synthesis and thus neuronal mitochondrial metabolism (Baslow, 2003) is not severely affected by MK801. However, decreased labeling of glutamate, GABA, and aspartate from $\left[1-{ }^{13} \mathrm{C}\right]$ glucose indicated somewhat decreased mitochondrial function in neurons in the CRFC. Glycolysis appeared normal as seen in unaltered alanine and lactate levels.

The increase of inositol in the temporal lobe is surprising since it is the only change in metabolite concentration detected in this brain region and may indicate glial swelling. Increase in inositol in the temporal lobe was also reported earlier (Brenner et al, 2005). Only a minor change was found in labeling in the temporal lobe in the present study, with cycling of label from $\left[1-{ }^{13} \mathrm{C}\right]$ glucose being increased in glutamate.

\section{Conclusions}

Injection of MK801 and other NMDA antagonists in rodents are considered appropriate schizophrenia models because these compounds induce both positive and negative symptoms in humans in contrast to other psychomimetics such as amphetamine (Tamminga et al, 2003). In the present study, repeated MK801 exposure led to increased glutamate concentration in the CRFC, which mimics the results seen in first episode schizophrenic patients. The decreased levels of $\left[4-{ }^{13} \mathrm{C}\right]$ glutamate, $\left[4,5-{ }^{13} \mathrm{C}\right]$ glutamate, and $\left[4,5-{ }^{13} \mathrm{C}\right]$ glutamine could eventually lead to the decrease in these metabolites seen in chronic patients. The present model appears very well suited to study the cascade of events taking place during the transition from first episode to chronic schizophrenia, and might help develop new treatment strategies. Furthermore, ${ }^{13} \mathrm{C}$ studies can also be carried out in humans and thus ${ }^{13} \mathrm{C}$ NMR spectroscopy might become a tool in treatment monitoring in patients. The imbalance in the glutamate homeostasis and thus impaired glial-neuronal interactions might contribute to disturbances in corticostriato-thalamo-cortical feedback.

\section{ACKNOWLEDGEMENTS}

This research was supported by the Norwegian Epilepsy Foundation. We thank Ivar Nordrum for the HE staining of the tissue. The excellent technical assistance of Bente Urfjell is gratefully acknowledged.

\section{REFERENCES}

Baslow MH (2003). N-acetylaspartate in the vertebrate brain: metabolism and function. Neurochem Res 28: 941-953.

Brenner E, Kondziella D, Håberg A, Sonnewald U (2005). Impaired glutamine metabolism in NMDA receptor hypofunction induced by MK801. J Neurochem 94: 1594-1603.

Brosnan-Watters G, Wozniak DF, Nardi A, Olney JW (1999). Parallel recovery of MK-801-induced spatial learning impairment and neuronal injury in male mice. Pharmacol Biochem Behav 62: 111-122.
Burbaeva GS, Boksha IS, Turishcheva MS, Vorobyeva EA, Savushkina OK, Tereshkina EB (2003). Glutamine synthetase and glutamate dehydrogenase in the prefrontal cortex of patients with schizophrenia. Prog Neuro-Psychopharmacol Biol Psychiatry 27: 675-680.

Carlsson M (1993). Hypothesis - are the disparate pharmacological profiles of competitive and un-competitive NMDA antagonists due to different baseline activities of distinct glutamatergic pathways? J Neural Transm 94: 1-10.

Carlsson M, Carlsson A (1989). The NMDA antagonist MK-801 causes marked locomotor stimulation in monoamine-depleted mice. J Neural Transm 75: 221-226.

Carlsson M, Carlsson A (1990). Interactions between glutamatergic and monoaminergic systems within the basal ganglia-implications for schizophrenia and Parkinson's disease. Trends Neurosci 13: $272-276$

Carlsson M, Carlsson A, Nilsson M (2004). Schizophrenia: from dopamine to glutamate and back. Curr Med Chem 11: 267-277.

Carlsson A, Waters N, Holm-Waters S, Tedroff J, Nilsson M, Carlsson ML (2001). Interactions between monoamines, glutamate, and GABA in Schizophrenia: new evidence. Annu Rev Pharmacol Toxicol 41: 237-260.

Do KQ, Trabesinger AH, Kirsten-Kruger M, Lauer CJ, Dydak U, Hell D et al (2000). Schizophrenia: glutathione deficit in cerebrospinal fluid and prefrontal cortex in vivo. Eur J Neurosci 12: 3721-3728.

Dracheva S, Elhakem SL, McGurk SR, Davis KL, Haroutunian V (2004). $\mathrm{GAD}_{67}$ and $\mathrm{GAD}_{65}$ mRNA and protein expression in cerebrocortical regions of elderly patients with schizophrenia. J Neurosci Res 76: 581-592.

Dringen R, Hirrlinger J (2003). Glutathione pathways in the brain. Biol Chem 384: 505-516.

Fix AS, Horn JW, Wightman KA, Johnson CA, Long GG, Storts RW et al (1993). Neuronal vacuolization and necrosis induced by the noncompetitive $N$-methyl-D-aspartate (NMDA) antagonist $\mathrm{MK}(+) 801$ (dizocilpine maleate): a light and electron microscopic evaluation of the rat retrosplenial cortex. Exp Neurol 123: 204-215.

Guidotti A, Auta J, Davis JM, Gerevini VD, Dwivedi Y, Grayson DR et al (2000). Decrease in reelin and glutamic acid decarboxylase $_{67}\left(\mathrm{GAD}_{67}\right)$ expression in schizophrenia and bipolar disorder. Arch Gen Psychiatry 57: 1061-1069.

Horvath ZC, Czopf J, Buzsaki G (1997). MK-801-induced neuronal damage in rats. Brain Res 753: 181-195.

Hossein Fatemi S, Stary JM, Earle JA, Araghi-Niknam M, Eagan E (2005). GABAergic dysfunction in schizophrenia and mood disorders as reflected by decreased levels of glutamic acid decarboxylase 65 and $67 \mathrm{kDa}$ and Reelin proteins in cerebellum. Schizophr Res 72: 109-122.

Janaky R, Ogita K, Pasqualotto BA, Bains JS, Oja SS, Yoneda Y et al (1993). Glutathione and signal transduction in the mammalian CNS. J Neurochem 73: 889-902.

Jentsch JD, Redmond Jr DE, Elsworth JD, Taylor JR, Youngren KD, Roth RH (1997a). Enduring cognitive deficits and cortical dopamine dysfunction in monkeys after long-term administration of phencyclidine. Science 277: 935-955.

Jentsch JD, Roth RH (1999). The neuropsychopharmacology of phencyclidine: from NMDA receptor hypofunction to the dopamine hypothesis of schizophrenia. Neuropsychopharmacology 20: 201-225.

Jentsch JD, Taylor JR, Roth RH (1998). Subchronic phencyclidine administration increases mesolimbic dopamine system responsivity and augments stress- and amphetamine-induced hyperlocomotion. Neuropsychopharmacology 19: 105-113.

Jentsch JD, Tran A, Le D, Youngren KD, Roth RH (1997b). Subchronic phencyclidine administration reduces mesoprefrontal dopamine utilization and impairs prefrontal 
cortical-dependant cognition in the rat. Neuropsychopharmacology 17: 92-99.

Kegeles LS, Abi-Dargham A, Zea-Ponce Y, Rodenhiser-Hill J, Mann JJ, Van Heertum RL et al (2000). Modulation of amphetamineinduced striatal dopamine release by ketamine in humans: implications for schizophrenia. Biol Psychiatry 48: 627-640.

Kosenko E, Llansola M, Montoliu C, Monfort P, Rodrigo R, Hernandez-Viadel M et al (2003). Glutamine synthetase activity and glutamine content in brain: modulation by NMDA receptors and nitric oxide. Neurochem Int 43: 493-499.

Krebs C, Fernandes HB, Sheldon C, Raymond LA, Baimbridge KG (2003). Functional NMDA receptor subtype $2 B$ is expressed in astrocytes after ischemia in vivo and anoxia in vitro. J Neurosci 23: 3364-3372.

Laruelle M, Kegeles LS, Abi-Dargham A (2003). Glutamate, dopamine, and schizophrenia: from pathophysiology to treatment. Ann NY Acad Sci 1003: 138-158.

Loscher W, Honack D (1991). Anticonvulsant and behavioral effects of two novel competitive $N$-methyl-D-aspartic acid receptor antagonists, CGP 37849 and CGP 39551, in the kindling model of epilepsy. Comparison with MK-801 and carbamazepine. J Pharmacol Exp Ther 256: 432-440.

Loubinoux I, Meric P, Borredon J, Correze JL, Gillet B, Beloeil JC et al (1994). Cerebral metabolic changes induced by MK-801: a 1D (phosphorus and proton) and 2D (proton) in vivo NMR spectroscopy study. Brain Res 643: 115-124.

Miller DW, Abercrombie ED (1996). Effects of MK-801 on spontaneous and amphetamine-stimulated dopamine release in striatum measured with in vivo microdialysis in awake rats. Brain Res Bull 40: 57-62.

Ohrmann P, Siegmund A, Suslow T, Spitzberg K, Kersting A, Arolt $\mathrm{V}$ et al (2005). Evidence for glutamatergic neuronal dysfunction in the prefrontal cortex in chronic but not in first-episode patients with schizophrenia: a proton magnetic resonance spectroscopy study. Schizophr Res 73: 153-157.

Olney JW (1989). Excitatory amino acids and neuropsychiatric disorders. Biol Psychiatry 26: 505-525.

Olney JW, Farber NB (1995). Glutamate receptor dysfunction and schizophrenia. Arch Gen Psychiatry 52: 998-1007.

Olney JW, Labruyere J, Price MT (1989). Pathological changes induced in cerebrocortical neurons by phencyclidine and related drugs. Science 244: 1360-1362.

Paxinos G, Watson C (1998). The Rat Brain in Stereotaxic Coordinates, 4th edn. Academic Press Limited: New York.

Rowland LM, Bustillo JR, Mullins PG, Jung RE, Lenroot R, Landgraf $\mathrm{E}$ et al (2005). Effects of ketamine on anterior cingulate glutamate metabolism in healthy humans: a 4 -T proton MRS study. Am J Psychiatry 162: 394-396.
Shank RP, Bennett GS, Freytag SO, Campbell GL (1985). Pyruvate carboxylase: an astrocytie-specific enzyme implicated in the replenishment of amino acids neurotransmitter pool. Brain Res 329: 362-367.

Sonnewald U, Kondziella D (2003). Neuronal glial interaction in different neurological diseases studied by ex vivo ${ }^{13} \mathrm{C} \mathrm{NMR}$ spectroscopy. NMR Biomed 16: 424-429.

Sonnewald U, Schousboe A, Waagepetersen H (2005). Neuronalastrocytic interactions (TCA cycling). In: Aschner M, Costa L (eds). The Role of Glia in Neurotoxicity, Part I, Functional Interaction Between Glia, Neurons and Endothelium, 2nd edn. CRC Press: Boca Raton, Florida, USA. pp 111-118.

Sonnewald U, Westergaard N, Schousboe A, Svendsen JS, Unsgard G, Petersen SB (1993). Direct demonstration by $\left[{ }^{13} \mathrm{C}\right] \mathrm{NMR}$ spectroscopy that glutamine from astrocytes is a precursor for GABA synthesis in neurons. Neurochem Int 22: 19-29.

Stanley JA, Williamson PC, Drost DJ, Rylett RJ, Carr TJ, Malla A et al (1996). An in vivo proton magnetic resonance spectroscopy study of schizophrenia patients. Schizophr Bull 22: 597-609.

Tamminga CA, Lahti AC, Medoff DR, Gao XM, Holcomb $\mathrm{HH}$ (2003). Evaluating glutamatergic transmission in schizophrenia. Ann NY Acad Sci 1003: 113-118.

Taylor A, McLean M, Morris P, Bachelard H (1996). Approaches to studies on neuronal/glial relationships by ${ }^{13} \mathrm{C}$ NMRS analysis. Dev Neurosci 18: 434-442.

Theberge J, Al-Semaan Y, Williamson PC, Menon RS, Neufeld RW, Rajakumar $\mathrm{N}$ et al (2003). Glutamate and glutamine in the anterior cingulate and thalamus of medicated patients with chronic schizophrenia and healthy comparison subjects measured with 4.0-T proton MRS. Am J Psychiatry 160: 2231-2233.

Theberge J, Bartha R, Drost DJ, Menon RS, Malla A, Takhar J et al (2002). Glutamate and glutamine measured with $4.0 \mathrm{~T}$ proton MRS in never-treated patients with schizophrenia and healthy volunteers. Am J Psychiatry 159: 1944-1946.

Volk DW, Austin MC, Pierri JN, Sampson AR, Lewis DA (2000). Decreased $\mathrm{GAD}_{67}$ mRNA expression in a subset of prefrontal cortical GABA neurons in subjects with schizophrenia. Arch Gen Psychiatry 57: 237-245.

Waniewski RA, Martin DL (1998). Preferential utilization of acetate by astrocytes is attributable to transport. J Neurosci 18: 5225-5233.

Wozniak DF, Brosnan-Watters G, Nardi A, McEwen M, Corso TD, Olney JW et al (1996). MK-801 neurotoxicity in male mice: histologic effects and chronic impairment in spatial learning. Brain Res 707: 165-179.

Wozniak DF, Dikranian K, Ishimaru MJ, Nardi A, Corso TD, Tenkova $\mathrm{T}$ et al (1998). Disseminated corticolimbic neuronal degeneration induced in rat brain by MK801: potential relevance to Alzheimer's disease. Neurobiol Dis 5: 305-322. 